\title{
THE INCLUSION OF STAKEHOLDER KNOWLEDGE AND PERSPECTIVES IN INTEGRATED ASSESSMENT OF CLIMATE CHANGE
}

\author{
PENNY KLOPROGGE and JEROEN P. VAN DER SLUIJS \\ Copernicus Institute for Sustainable Development and Innovation, Utrecht University, \\ Heidelberglaan 2, 3584 CS Utrecht, The Netherlands \\ E-mail:p.kloprogge@chem.uu.nl
}

\begin{abstract}
Over the past few decades Integrated Assessment (IA) has emerged as an approach to link knowledge and action in a way that is suitable to accommodate uncertainties, complexities and value diversities of global environmental risks. Responding to the complex nature of the climate problem and to the changing role of climate change in the international climate policy process, the scientific community has started to include stakeholder knowledge and perspectives in their assessments. Participatory Integrated Assessment (PIA) is in its early stage of development. Methodology varies strongly across PIA projects. This paper analyzes four recent IA projects of climate change that included knowledge or perspectives from stakeholders in one-way or another. Approaches and methods used turn out to differ in whether stakeholders are involved actively or passively, whether the approach is bottom-up or top-down, and whether the different functions in the IA process are open or closed to stakeholder input. Also, differences can be seen in the degree to which boundaries are pre-set that limit the roles and domains of competencies attributed to each scientific or non-scientific participant (so-called boundary work). The paper discusses pros and cons of the various approaches identified, and outlines heuristics and considerations to assist those who plan, design or fund new IA processes with stakeholder input on what approaches best to choose in view of the objectives for stakeholder involvement, in view of the role that the IA plays in the overall risk management process and in view of considerations regarding boundary work.
\end{abstract}

\section{Introduction}

Managing the risks of anthropogenic climate change is a societal process, which has to deal with a long-term complex issue under conditions of high and partly irreducible uncertainties and multiple value orientations of the many national and international stakeholders. There are uncertainties both regarding the mechanisms of the climate system, and regarding future societal developments. The multiple value orientations mostly have to do with the interpretation of scientific information by the stakeholders, and the actions they think should or should not be taken to deal with climate change. We here define stakeholders as those actors who are directly or indirectly affected by an issue and who could affect the outcome of a decision making process regarding that issue or are affected by it (World Bank, 1996).

Over the past few decades Integrated Assessment (IA) has emerged as an approach to link knowledge and action in a way that is suitable to accommodate 


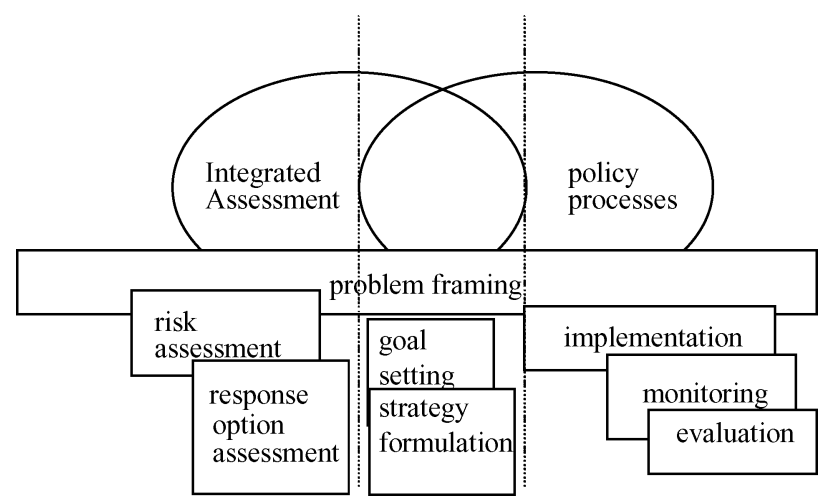

Figure 1. The different functions in the process of environmental risk management and the position of IA within this broader context.

uncertainties, complexities and value diversities of global environmental risks (Sors et al., 1997). In its ideal form, IA can be defined as an interdisciplinary process of combining, interpreting and communicating knowledge from diverse scientific disciplines in such a way that the whole set of cause-effect interactions of a problem can be evaluated from a synoptic perspective with two characteristics: (i) it should have added value compared to single disciplinary assessment; and (ii) it should provide useful information to decision makers (Rotmans and Dowlatabadi, 1997). ${ }^{1}$

IA and policy processes partly overlap (Bailey et al., 1996): IA practitioners interact with users of IAs in the policy development field. When dealing with risk issues, such as climate change, the activities in IA and policy processes together can be viewed as a risk management process. The risk management process can be subdivided in risk management functions (Kates et al., 1985). In Figure 1 we have schematically sketched the relations between IA, the policy process and these risk management functions.

These functions, which were used by the project Social Learning in the management of Global Environmental Risks (The Social Learning Group, 2001; Toth and Hizsnyik, 1998) distinguish: risk assessment, option assessment, goal and strategy formulation, implementation, monitoring, and evaluation. In case of the issue of climate change, risk assessment addresses the understanding about the nature, causes, consequences, likelihood and timing of climate change. Option assessment addresses the feasibility, costs and benefits of possible options to manage a risk. Goal and strategy formulation involve the setting of management goals, the design of a package of options appropriate for achieving them, and the selection of modes for implementing those options. Implementation involves actions actually taken by various actors (including governments) to manage climate change. Monitoring involves documenting actual changes in aspects of the environment affected by climate change, and the results of management strategies and specific implementation 
measures. Evaluation encompasses self-conscious efforts of actors to reflect upon and evaluate their own and others' performance on climate risk management. We have added to this set of functions the function of problem framing which contains the setting of problem boundaries and problem definition. Another alteration in this set of functions is that we will refer to the option assessment function as 'response option assessment function' for clarity reasons. The IA process generally comprises the functions problem framing, risk assessment, response option assessment, and generally assists in goal setting and strategy formulation (Figure 1). Implementation, monitoring and evaluation are typically functions that can be found in policy processes.

Stakeholder knowledge and perspectives can be involved in both IA and policy processes. There is a long-standing tradition of involving stakeholders in decisionmaking processes regarding complex environmental problems (for a comprehensive review, see for instance, Yosie and Herbst, 1998). Involving stakeholders in IA, however, is relatively new. In the early stages of its development, IA of climate change was mainly the domain of experts from the natural sciences. Technical computer models largely dominated the field. In the 1990s participatory methods came to be generally applied tools in the field of IA, be it with varying success. Participatory methods enable IA experts to identify, articulate and incorporate specific (non-scientific) knowledge of the stakeholders in the IA process, and to incorporate the diversity of their views on the causes, effects, relevant aspects of, and solutions to the problem.

In a setting in which science and policy are intertwined, the boundaries between these two domains become contested. The sociologist Thomas Gieryn (1983) calls this boundary work. Parts of a debate are depoliticised by defining them as belonging to the scientific domain or parts are politicised by defining them as belonging to the policy domain (Gieryn, 1983). Jasanoff (1990) has explored how scientists use a variety of boundary-defining strategies to establish who is in and who is out of relevant peer groups and networks of prestige or authority. By drawing boundaries between science and policy, scientists post 'keep out' signs to prevent non-scientists from challenging or reinterpreting claims labelled as 'science'. Boundary work results in a demarcation of domains defining who is seen as competent in specific areas of the problem, either by defining the issue or the persons involved as belonging to a certain domain. The boundaries between the domains of competence involved in a debate usually remain subject to continuous re-negotiations. As science and policy are intertwined in IA, this demarcation of domains can be expected in integrated assessment activities. When non-scientific stakeholders are involved in the IA process, boundary work is often clearly observable, as we will argue later on.

The current literature reviewing PIA methods presents inventories of methods to engage non-scientists in Integrated Environmental Assessment and classifies these methods in different ways: Toth and Hizsnyik (1998) distinguish between building models together, teaching and training games, policy exercises to explore alternative 
futures, and IEA focus groups to involve citizens. Rotmans (1998) distinguishes three classes of methods: dialogue methods, policy exercises and mutual learning methods. Van Asselt and Rijkens-Klomp (2002) identify eight different participatory methods currently in use in the field of IA: focus groups, scenario analysis, scientists stakeholder workshops, policy exercises, participatory modelling/group model building, citizens' juries, consensus conferences and participatory planning. Van de Kerkhof (2004) discusses five participatory methods as representatives of the broad range of participatory methods: the dialectical debate, the decision seminar, the policy Delphi, group brainstorming, and gaming simulation.

Although such overviews and classifications are useful, they focus more on differences in ways to engage stakeholders in IA than on ways to elicit and include non-expert knowledge and perspectives in the assessments. Involving stakeholder knowledge and perspectives does not always require that actual stakeholders are personally involved in the IA process. The existing studies show little appreciation for the distinguishing characteristics between PIA methods as regards the way that stakeholder knowledge and perspectives are included in the assessment process.

In this paper, based on four case studies, we analyse the distinguishing characteristics regarding the way in which stakeholder knowledge and perspectives are incorporated in the IA processes studied. We further discuss strengths and weaknesses of the approaches identified and highlight typical pitfalls. Insights in the distinguishing characteristics provide heuristics to assist those who plan, design or fund new IA projects in selecting appropriate methods and in effective design of new IA processes involving stakeholder views. Our recommendations do not point in the direction of specific methods that should be used in certain situations, but rather offer insight in the requirements that a method for involving stakeholder views should meet. These requirements are identified in view of the objectives one may have with involving stakeholder knowledge and perspectives, in view of the role of an IA process in the overall risk management process of climate change, and in view of considerations regarding boundary work.

The following questions were addressed in our study:

- What are motives for involving stakeholder knowledge and perspectives in IA of climate change?

- How have stakeholder knowledge and perspectives been included in IA of climate change?

- In what way and to what extent did boundary work occur in these IA processes?

- How can stakeholder knowledge and perspectives best be included in IA of climate change?

We selected four IA processes in which stakeholder knowledge and perspectives are involved, all addressing the climate change problem. The cases were selected 


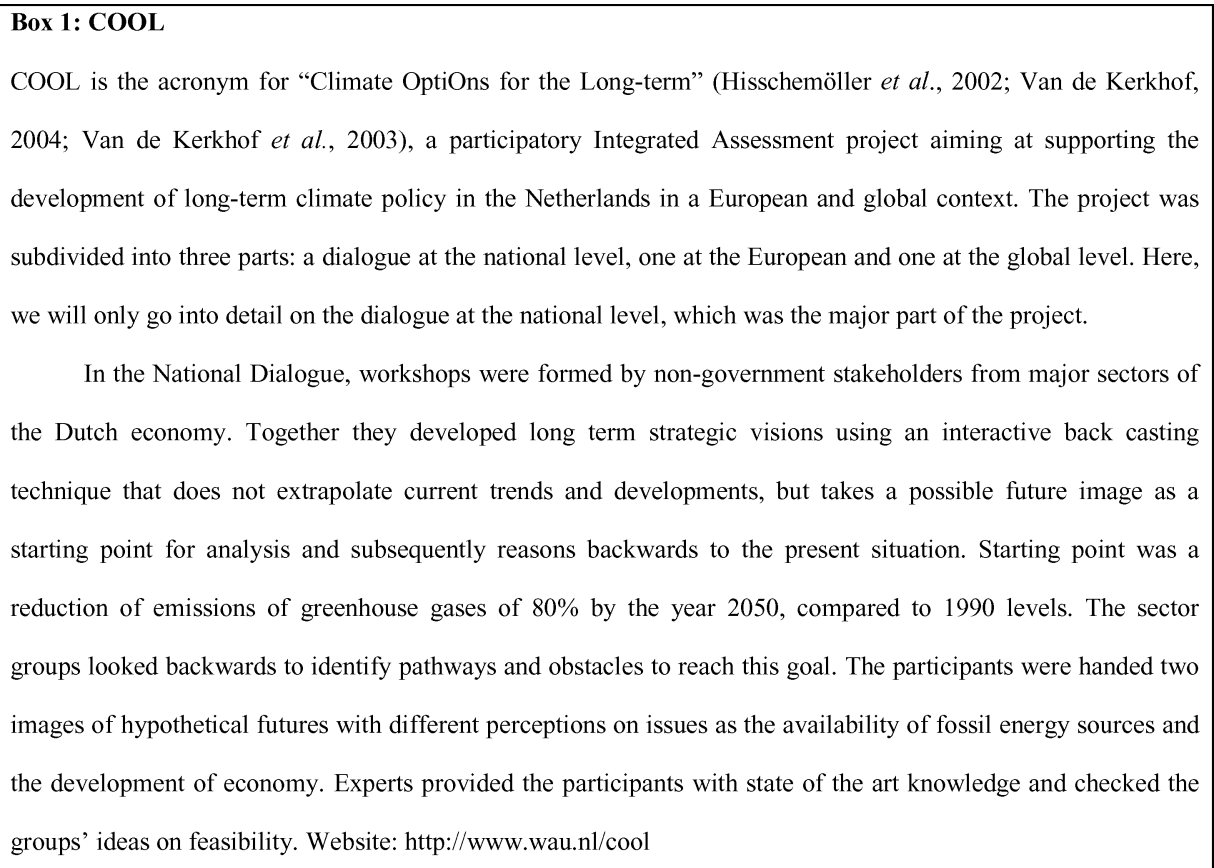

because of the diverse ways in which stakeholder views are included in the IA and because of the availability of data. The cases we explored are: COOL (in which stakeholders together explored how a predefined emission reduction goal can be reached), Risk Approaches (in which the constructs that stakeholders use to think about climate change were explored), TARGETS (an IA model in which different perspectives on climate change are incorporated), and ULYSSES (in which citizens reported their insights on climate change based on discussions and the use of IA models). A description of these projects is given in Boxes 1-4.

The motives for involving stakeholder views are discussed in Section 2. Section 3 deals with the question how stakeholder views have been included in the four case-studies. In Section 4 we explore how boundary work may have played a role in these processes. Our recommendations for including stakeholder views in IA of climate change are formulated in Section 5. Our paper concludes with discussion and conclusions in Section 6.

\section{What are Motives for Involving Stakeholder Knowledge and Perspectives?}

As we will argue below, the inclusion of stakeholder knowledge and perspectives in IA of climate change can be motivated both from a scientific and a policy point of view. 


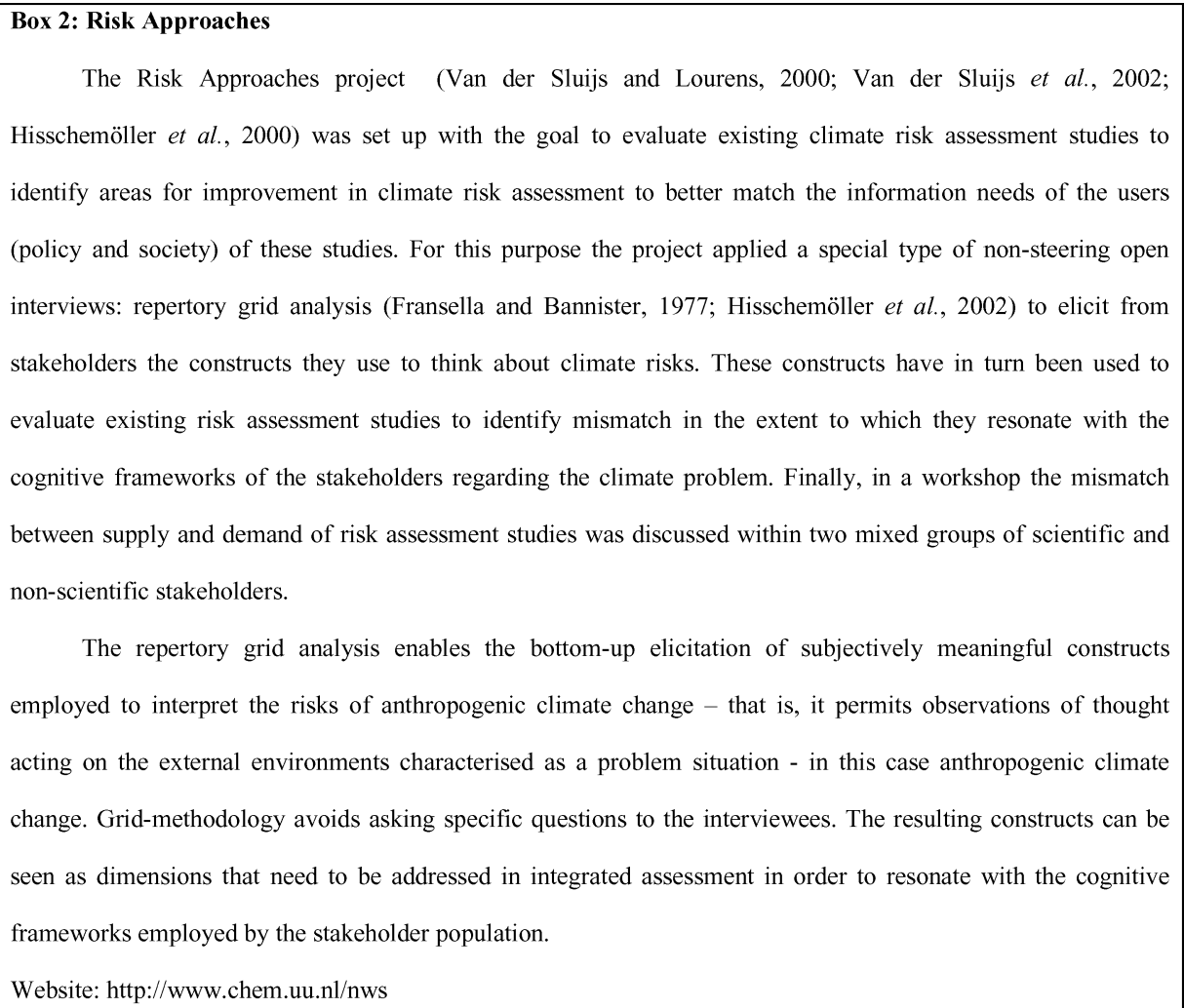

\subsection{THE SCIENTIFIC NATURE OF THE PROBLEM OF CLIMATE CHANGE AND THE INCLUSION OF STAKEHOLDER INPUT IN IA}

Climate change is a problem in which facts are uncertain, values are in dispute, stakes are high and decisions may well be urgent. Problems with these characteristics cannot be handled by the 'normal', truth seeking science alone, but require a different problem coping strategy known as post-normal science (Funtowicz and Ravetz, 1992, 1993; Ravetz and Funtowicz, 1999; Van der Sluijs, 1997, 2001, 2002). As long as scientific uncertainties and decision stakes are high, the aim of finding the 'solution to the scientific puzzle' is in principle unachievable. The questions put to science by the policy process are urgent so we cannot wait until science has the ultimate answer. Acting as if science would be able to handle this problem in the same puzzle-solving mode as experimental sciences in the controlled conditions of the laboratory would be misleading because it creates false expectations that science can yield conclusive answers to these problems (Van der Sluijs, 1997). Instead, a post-normal science is needed that aims at common commitments to approaches for dealing with uncertainty and value diversity in such complex policy issues. 


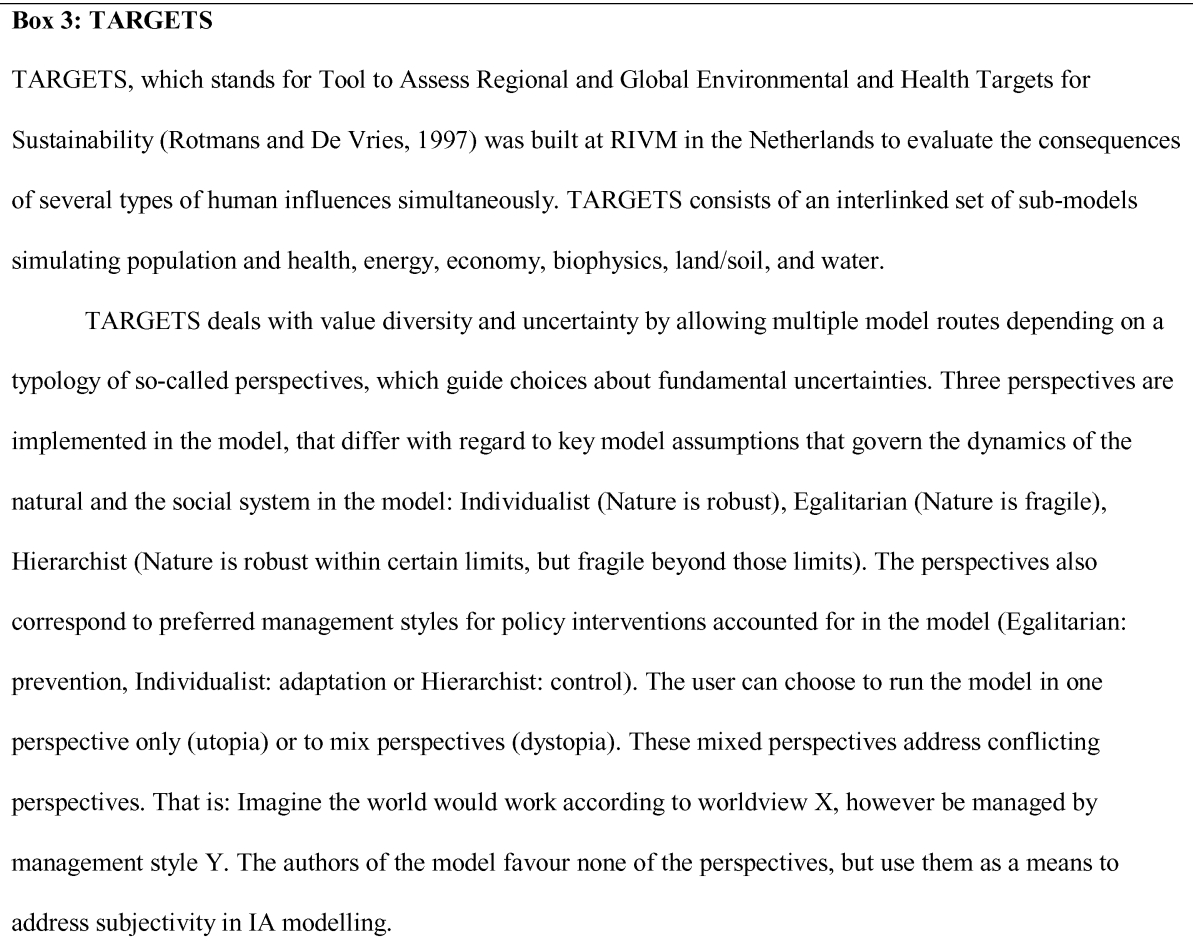

Because of the many uncertainties, traditional science is not able to sufficiently legitimize drastic steps that may be needed to deal with climate change. The traditional dominance of 'hard facts' over 'soft values' has been inverted: hard value commitments may have to be made, based on soft facts (Funtowicz and Ravetz, 1993). The assessment of risks and the setting of policy should therefore encompass public agreement and participation. In addition, participation is desirable to enhance the quality of the scientific input in the process. When facing the uncertainties involved in post-normal problems, scientists are lay people as well (Funtowicz and Ravetz, 1993). Stakeholders' reasoning, observation and imagination are not bounded by scientific rationality; this can be beneficial when tackling ill-structured complex problems. Consequently, the knowledge and perspectives of the stakeholders can bring in valuable new views on the problem and relevant information on that problem. The latter is known as 'extended facts'. Stakeholders can contribute to knowledge in a number of ways. These include contributing knowledge on local conditions which may help determine which data are strong and relevant or which response options are feasible; providing personal observations of climate change and its effects which may lead to new foci for empirical research addressing dimensions of the problem which were previously overlooked; and creative thinking of mechanisms and scenarios through which projected climatic changes 


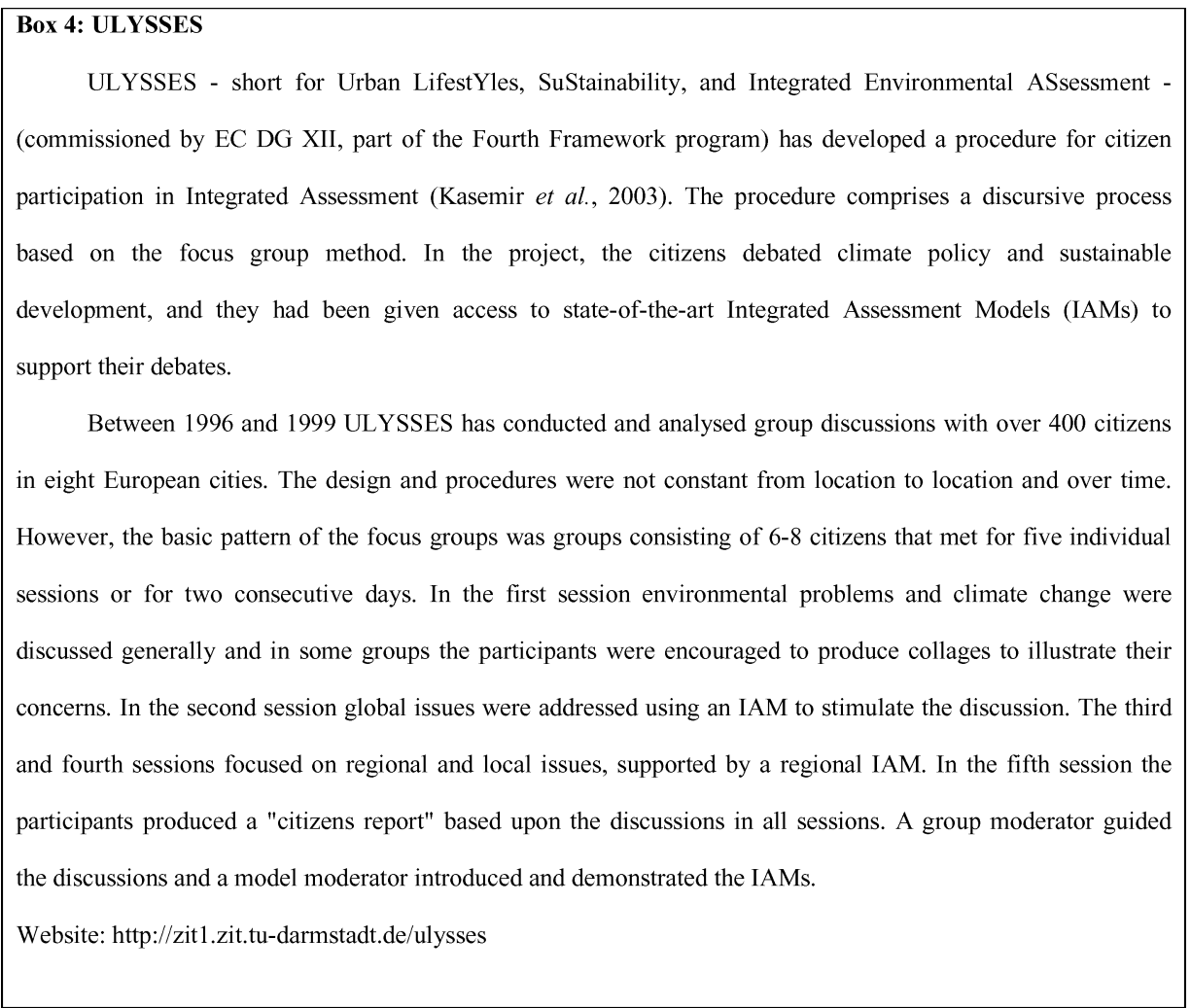

may affect different sectors of society. In the view of post-normal science scientific and technical discourse in problems like climate change should no longer be restricted to expert communities but should include non-specialist knowledge, wisdom, and perspectives of stakeholders on the problem at hand. Making full use of this reservoir of scrutiny-potential requires the establishment of an extended peer community (Funtowicz and Ravetz, 1996) and the inclusion of stakeholder knowledge and perspectives not only in the function where response options are debated, but also in the problem framing and risk assessment processes that precede it.

Reasoning from the concept of post-normal science, inclusion of knowledge and perspectives of stakeholders in IA is necessary for handling uncertainty, disagreement and dissent in risk assessment and the setting of policy, for the enhancement of the quality of the assessment and for legitimisation of action taken in the policy process and of the science that underpins the choice for that action. Involving stakeholders in the development and application of a problem solving strategy further allows for a democratic approach to the problem (see also Stern and Fineberg, 1996). 


\subsection{THE INTERNATIONAL POLICY PROCESS OF CLIMATE CHANGE AND THE INCLUSION OF STAKEHOLDER INPUT IN IA}

The purpose of IA is to provide insights for policy processes. Developments in the IA field therefore are closely related to developments that take place in the policy field. The development of international climate policy till the year 2004 can roughly be divided into seven periods (adapted from Sprinz and Luterbacher, 1996; see also Van der Sluijs, 2001):

- The foundational period, during which scientific concern about global warming developed;

- The agenda-setting phase, from 1985-1988, when climate change was transformed from a scientific into a policy issue;

- A pre-negotiation period from 1988-1990, when governments became heavily involved in the process;

- The formal intergovernmental negotiations phase, leading to the adoption of the United Nations Framework Convention on Climate Change (FCCC) in May 1992;

- A post-agreement phase focusing on the elaboration and implementation of the FCCC and the initiation of negotiations on additional commitments;

- The establishment of the Kyoto Protocol in 1997 with quantified greenhouse gas emission reduction targets for industrialized countries ('Annex 1 countries') for a first budget period until 2010;

- A post-Kyoto/pre-ratification period in which detailed credit systems for the flexible mechanisms from the Kyoto Protocol are negotiated, and the formal coming into force of the Kyoto protocol is jeopardised.

IA started to play a role in the agenda-setting phase: the 1985 Villach international Conference on the Assessment of the role of Carbon Dioxide and of Other Greenhouse Gases in Climate Variations and Associated Impacts (Bolin et al., 1986) was a milestone in bringing together experts from a multitude of scientific disciplines to arrive at an integrated view on the climate problem. Three years later, the World Conference on the Changing Atmosphere: Implications for Global Security held in Toronto (World Meteorological Organisation, 1989) marked the beginning of high-level political debate on the risks of anthropogenic climatechange. The Villach and Toronto conferences were successful attempts by scientists to put the issue of climate change on the policy agenda and to initiate the first steps of an international climate policy regime. In the pre-negotiation phase, climate IA models started to be developed (for a comprehensive historic review see: Van der Sluijs, 1997, 2001). In this phase, scenario analyses were needed to support the thinking about how much greenhouse gas emissions needed to be reduced in order to keep the risks of climate change caused by human behaviour within manageable proportions. In the post-agreement phase of the 
international climate policy regime, in which quantified emission limitations and reduction objectives were negotiated, IA model-results from different modelling groups were fed into the negotiations. A key example of IA-results produced in this phase has been the study on 'safe landing corridors' (tolerable windows) (Berk et al., 2001), defined as the allowable lower and higher bounds of greenhouse gas emission scenarios, related to a set of criteria for climate policy whose purpose is to protect the environment, the food production, and the economy from disruption.

With the Kyoto protocol, a long-term effort has started to design possible institutions and mechanisms whose implications are being gradually explored by international environmental diplomacy (Kasemir et al., 2003). In the post-Kyoto/preratification period detailed credit systems for the flexible mechanisms from the Kyoto Protocol (Joint Implementation, Clean Development Mechanism, emission trading, sinks) were negotiated in Buenos Aires, Bonn/Marakech, and Milano. The formal coming into force of the Kyoto Protocol failed to occur when the U.S. Bush Administration withdrew and Russia postponed ratification because low demand on Russia's 'hot air' (unused Kyoto emission rights) in absence of U.S. participation drove down the expected market price and thus Russia's expected economic benefits. IA was used in this phase to demonstrate how the proposals and agreements on credit systems for flexible mechanisms had watered down the environmental effectiveness of the Kyoto Protocol. Also, IA was used to assess macro economic effects of flexible mechanisms under different ratification scenarios, showing that even without the U.S., ratification by Russia would bring Russia significant economic benefit. Further, IA focussed in this phase on the exploration of emission reduction differentiation schemes for the second budget period and for the participation of non-annex-1 countries in the Kyoto regime (e.g., Berk et al., 2001).

To develop environmental policies on a global scale it is essential to build up the know-how and the relations of trust between the parties involved. It is suggested by Kasemir et al. (2003) that actions taking place at the level of international environmental diplomacy must be combined with actions involving various kinds of stakeholders, if effective climate policy is to emerge. The successful implementation of measures to mitigate greenhouse gas emissions requires consumer and worker co-operation as well as the consent of citizens.

Throughout the last decade of the previous century numerous projects involved stakeholders in IA-activities. There was a growing need for the integration of social science research in IA, and in particular of methods and techniques to include stakeholder knowledge and perspectives in the assessment process (Kasemir et al., 2003). The shift of IA with a purely scientotechnical analytical toolbox to IA with a toolbox with complementary analytical and participatory methods in climate risk assessment can be seen as an inevitable response to the changing characteristics and requirements of the international climate policy process. 


\section{How have Stakeholder Knowledge and Perspectives been Included?}

For each of the four IA cases we selected, we studied how stakeholder knowledge and perspectives were included during the project. In Section 3.1 we describe whose perspectives have been involved in the cases, in Section 3.2 we discuss in which risk management functions this involvement took place. Finally, Section 3.3 describes the way in which the stakeholders' input was taken into account in the IA process.

\subsection{WHOSE KNOWLEDGE AND PERSPECTIVES HAVE BEEN INVOLVED?}

In COOL, Risk Approaches and ULYSSES the knowledge and perspectives of stakeholders were brought into the IA by involving stakeholders in the process. These projects varied in the type and number of stakeholders that were involved. Each of the IA projects motivated its selection of stakeholders on the basis of the purpose of the project. The purposes are elaborated upon in Boxes 1-4.

The ULYSSES project focused mainly on citizens and their views on climate change and sustainability. A total of 400 citizens participated in IA focus groups in 8 European cities. The basic pattern of the focus groups was 6-8 participants. COOL and the Risk Approaches project aimed at involving persons across the broad spectrum of stakeholders, acting on their own behalf (not as representatives of stakeholder groups). In the Risk Approaches project 27 persons were involved from business, NGO's, ministries and research institutes. Approximately 66 stakeholders were involved in the COOL project, grouped into four dialogue groups, each covering green house gas emission reduction in one the following sectors of the Dutch economy: industry and energy; agriculture and nutrition; housing and construction; and traffic and transport. The backgrounds of the stakeholders were business, NGO's, governmental organisations, consultancy firms, energy companies, advisory boards and research institutes. The TARGETS project did not involve actual stakeholders. TARGETS applied a theoretical ideal-typical representation of stakeholder perspectives rather than involving actual stakeholders. Three perspectives are distinguished within the TARGETS model, that differ with regard to key assumptions about nature and society: Individualist (Nature is robust), Egalitarian (Nature is fragile), Hierarchist (Nature is robust within certain limits, but fragile beyond those limits). These perspectives have been developed as ideal types in the so-called cultural theory of risks (Douglas and Wildavsky, 1982). These three perspectives can be seen to span up the policy relevant part of the spectrum of value diversity in the stakeholder community.

A summary of perspectives involved in the four IA processes is presented in Table I. 


\section{TABLE I}

Stakeholder perspectives involved in each project

\begin{tabular}{|c|c|}
\hline Project & Whose perspectives were involved? \\
\hline COOL & $\begin{array}{l}\text { Approximately } 17 \text { stakeholders from business, } 18 \text { from NGO's, } 8 \text { from } \\
\text { governmental organisations, } 5 \text { from consultancy firms, } 2 \text { from energy } \\
\text { companies, } 2 \text { from advisory boards, } 14 \text { from research institutes. }\end{array}$ \\
\hline Risk Approaches & $\begin{array}{l}\text { Twenty-seven (potential) users of climate risk assessment in the Netherlands: } \\
\text { business 10; environmental NGOs 5, research managers 5, Ministries } 7 \text {. }\end{array}$ \\
\hline TARGETS & $\begin{array}{l}\text { Three ideal typical perspectives, which are assumed to capture the policy } \\
\text { relevant part of the societal spectrum of value-orientations: Hierarchist, } \\
\text { Egalitarian and Individualist. }\end{array}$ \\
\hline ULYSSES & $\begin{array}{l}400 \text { Citizens in } 8 \text { European cities; plus a smaller sample of decision makers } \\
\text { from public policy and the private sector, representatives from the } \\
\text { financial industry interested in ecological investment, and media } \\
\text { representatives. }\end{array}$ \\
\hline
\end{tabular}

TABLE II

This table maps which risk management functions were addressed for each of the IA projects

\begin{tabular}{|l|l|l|l|l|}
\hline & COOL & $\begin{array}{l}\text { Risk } \\
\text { Approaches }\end{array}$ & TARGETS & ULYSSES \\
\hline Problem framing & & & & \\
\hline Risk assessment & & & & \\
\hline $\begin{array}{l}\text { Response } \\
\text { option } \\
\text { assessment }\end{array}$ & & & & \\
\hline $\begin{array}{l}\text { Goal setting } \\
\text { Strategy } \\
\text { formulation }\end{array}$ & & & & \\
\hline
\end{tabular}

Note. Dark grey shading indicates the main management functions that were addressed, light grey shading indicates that these management functions were addressed to a lesser degree.

\subsection{WHICH RISK MANAGEMENT FUNCTIONS WERE ADDRESSED IN THE PROJECTS?}

In Table II we provide an overview of the risk management functions addressed in the IA projects we studied. 
The COOL project addressed the goal-setting function in that the starting point of the project was an $80 \%$ reduction of greenhouse gases compared to 1990 levels by the middle of the twenty-first century. The sector groups involved in the dialogue identified major technological options for emission reduction, as well as barriers and opportunities concerning options. Based on these discussions, they developed strategic visions for drastic emission reduction containing their views on political choices, conditions that have to be met, and views on when and how the options should be implemented (Van de Kerkhof, 2004). The COOL project thus addressed the response option function, strategy function, and to a lesser extent the goal-setting function.

In the Risk Approaches project it was studied whether there is a mismatch between the supply and demand of risk assessment studies (Van der Sluijs et al., 2002). The rationale behind the Risk Approaches project was to minimise occurrence of what Dunn calls type-III error: assessing the wrong problem by incorrectly accepting the false meta-hypothesis that there is no difference between the boundaries of a problem as defined by the analyst and the actual boundaries (Raifa, 1968, redefined by Dunn, 1997). The remedy proposed by Dunn to cope with this type of uncertainty is context validation (Dunn, 1998, 2001). Context validity refers to the validity of inferences that we have estimated the proximal range of rival hypotheses. Context validation can be performed by a participatory process to elicit from stakeholders rival hypotheses on causal relations underlying a problem and rival problem definitions. By identifying the constructs that stakeholders use to think about climate change, the Risk Approaches project explored how they see the problem and what information they need. The Risk Approaches project thus mainly was concerned with the problem framing function. Since also constructs regarding risk assessment and options were addressed the project to some extent paid attention to the risk assessment and response option functions.

In the IA model TARGETS many of the risk assessment functions are addressed. The model was built for explorations of the problem of climate change viewed from different perspectives on how the world works and on how it should be managed. The problem framing function therefore is clearly addressed. In TARGETS the PressureState-Impact-Response (PSIR) framework was used (Rotmans and De Vries, 1997). The state of the natural and social systems (State) is affected by social, economic and ecological driving forces (Pressure) and human intervention (Response). As a result of human and/or natural disturbances impacts arise (Impacts). The impacts may directly be affected by the response system or may indirectly be affected by responses that alter the pressure and/or the state dynamics system. Using this framework the nature, causes and consequences of climate change, and response options are addressed (risk assessment function and response option function). Rotmans and De Vries (1997) describe simulation experiments conducted with the model. Exploring utopian and dystopian futures allows conclusions on which strategies seem to be robust when viewing the problem from different angles and which strategies seem to prevent dystopian futures (strategy formulation function). 
Also, for each of the three world views tentative target $\mathrm{CO}_{2}$ concentration levels were set (goal-setting function).

In the ULYSSES project, groups of citizens had several meetings in which they reflected and debated on the problem of climate change having access to expert information and IA models related to global and local change (Querol et al., 1999). In the final meeting the participants wrote a 'citizen report' describing among others whether they think climate change is a problem, how one should live in 30 years time, how much energy use is appropriate in different sectors, and when action should be taken and by whom. The project thus addressed the problem framing, risk assessment, response option, and strategy formulation function. With respect to regional climate change also local policy goals were discussed (Kasemir et al., 1999) (goal-setting function).

\subsection{IN WHAT WAY HAVE STAKEHOLDER KNOWLEDGE AND PERSPECTIVES BEEN INCLUDED?}

Each of the four cases we looked at applied another method for involving stakeholder knowledge and perspectives: COOL used dialogue-workshops using a back casting technique, Risk Approaches applied repertory grid analysis to elicit from stakeholders constructs they apply to think about climate change, TARGETS used ideal types of stakeholder' perspectives based upon Cultural Theory of risk, and ULYSSES used IA focus groups with open ended discussions. The methods vary in terms of the extent to which and the way in which the knowledge and perspectives are brought into the project, and the nature of the involvement of stakeholders. In this study, we identified three distinguishing characteristics when looking at the design of the four IA projects:

- Passive or active stakeholder involvement;

- The degree to which different functions of the IA process are open or closed for stakeholder input;

- Bottom-up or top-down approach to knowledge and perspectives.

In the next sections, we discuss these three categories and analyse how the involvement of stakeholder input took place in the four IA cases.

\subsubsection{Passive or Active Involvement}

In case of active stakeholder involvement, the stakeholders participate directly and actively in the IA process. They act either as a representative of a stakeholder group or as an individual, and contribute their perspectives and knowledge in the IA. In the case of passive stakeholder involvement the IA experts make an inventory of stakeholder knowledge and perspectives and subsequently incorporate these in the assessment.

In the COOL and ULYSSES project the stakeholders were actively involved: through moderated discussions and debate they themselves brought their knowledge 
and perspectives into the IA process. In the Risk Approaches project the stakeholders' views on climate change were elicited in one to one interviews between project members and stakeholders. The stakeholders did not interact with each other and did not play an active role in the interpretation and synthesis of the results. This is a case of passive involvement. No stakeholders at all were involved in the TARGETS project. The perspectives that stakeholders may have on climate change were captured in three world views based on cultural theory. The project members translated these ideal types into differing model structure and assumptions, and differing management styles for policy interventions for the different worldviews. This can be considered as passive involvement of stakeholder views.

\subsubsection{Open or Closed}

A risk management function can be considered 'open' with respect to the participation of stakeholders, if the contents and results of the function have not a priori (i.e., before the interaction with stakeholders) been established by the IA experts. The risk management function can then be co-shaped by the stakeholders. In a fully closed process, the IA experts or their clients establish the results of the function and leave no room for changes due to input of the stakeholders. Several degrees of 'openness' can be distinguished, from consultation to co-production (see also Mostert, 2003).

In case of the TARGETS project the risk management functions were closed for direct input of stakeholders: the ideal types were deducted from Cultural Theory and the translation of these types into alternative model routes was carried out by the project members. In the COOL project the goal-setting function was closed: the (hypothetical) goal for the emission reduction to be achieved by the year 2050 was a priori established by the project members in collaboration with policy-makers. This approach had the advantage that the participants were committed to a highly focused creative process, exploring concrete and feasible pathways, which could make a long-term transition to a low carbon economy attainable. It has the disadvantage that those stakeholders who do not share the conclusion that such a transition is necessary may feel excluded from the process. The response option and strategy formulation functions were open. The input from the project team consisted of procedural input (e.g., moderating the discussions); the design of two hypothetical future worlds with low carbon intensity for the backcasting exercise; providing the stakeholders with basic scientific information on climate change and emission reduction options; and providing scientific information at the request of the participants (Van de Kerkhof, 2004). All risk assessment functions addressed in the Risk Approaches project were open. The project team's contribution to these functions was purely procedural (namely eliciting the constructs from the stakeholders). In the ULYSSES project as well all risk assessment functions addressed were open. In discussions and debate the citizen participants developed their own view on climate change and reported the results in citizens' reports. Although scientific information was actively brought in by experts and played an important role in the project, the 
participants were enabled to discuss issues in the IA focus groups before this information was presented (Querol et al., 1999). Also, the use of concepts and analytical terms by the moderators was avoided. This limits the influence of the project team on what and how issues are discussed.

\subsubsection{Bottom-Up or Top-Down Approach}

When stakeholder perspectives are included using a bottom-up approach, actual stakeholder viewpoints on specific issues are explored, which may then be aggregated into more general classifications of ideas. If a top-down approach is used, viewpoints on specific issues are deducted from general classifications of ideas (e.g., ideal types such as world views from Cultural Theory or storylines as used by the Intergovernmental Panel on Climate Change (IPCC) for emission scenarios, Nakicenovic and Swart, 2000).

This top-down approach can clearly be seen in the TARGETS project, where different model structures and assumptions were developed for each of the Cultural Theory ideal types used. Although TARGETS has been path-breaking in the sense that it acknowledges the possibility of multiple problem structures - both at the level of causal mechanisms behind the problem and on the level of preferences and values - and in that it recognises the legitimacy of different perspectives on the science, this method has a shortcoming in that it restricts the problem structuring to three different static problem definitions in terms of pre-defined categories. By doing so, the integration of differing perspectives and differing value positions into new ways of looking at the problem is hampered.

In the other three projects a bottom-up approach was used. In COOL and ULYSSES group discussions took place on specific issues (emission reduction options and the problem of climate change respectively), without introducing ideas from general classifications. In the ULYSSES project the group moderators even avoided introducing concepts and analytical terms (such as 'environment' and 'global warming') to encourage the participants to talk about their own concerns (Darier et al., 1998).

In the Risk Approaches project constructs that stakeholders use to think about climate change were elicited using the repertory grid method. This method has its roots in cognitive psychology (Fransella and Bannister, 1977) and is widely applied in the field of marketing research. Grid-methodology avoids asking specific questions to the interviewees. Instead, the interviewer uses a set of cards, containing the so-called elements that determine the focus of the interview. The Risk Approaches project used two sets of elements. The first set had 12 cards each describing a different impact of climate change. The set was designed such that it covers a wide range of impacts of climate change including impacts of climate policy. The other set had 12 cards each describing a different policy option to respond to climate change. This set also was designed to cover a wide spectrum of policy options. As a stimulus, the respondent was presented three cards randomly drawn from one set and was then asked to indicate how two of these three climate impacts (respectively 
climate options) were alike and different from the third regarding an aspect that he or she deemed relevant for the climate debate. The respondent's answer is what repertory grid analysis calls a construct. For each respondent, the procedure was repeated until the respondent did not produce new constructs. Then the respondent was asked to select the three most important constructs from the list he or she had generated. For these three constructs the respondent was asked to score the extent to which this construct applied to each of the elements from the set. Through statistical analysis techniques for optimal scaling (HOMALS) the major dimensions or criteria that respondents use to evaluate information about climate change risks could be identified. Constructs were thus elicited in a bottom-up manner and later on converted into more general categories (Van der Sluijs et al., 2002). One could argue that such an open bottom-up process to include stakeholder perspectives (be it rival hypotheses on a problem or rival constructs used to judge a problem) is endless as there are as many different perspectives as there are different individual stakeholders, and one does not know when one has covered the whole range of perspectives in the stakeholder community. However, it has been shown that in projects where such elicitation processes were used, the cumulative distribution of unique rival hypothesis flattens out after having interviewed or consulted a limited number of stakeholders, usually somewhere between 20 and 25 .

In the Risk Approaches project this so-called 'saturation rule' was also observed (see Figure 2). This confirms the validity of the assumption that inclusion of a sample of about 20-25 stakeholders (chosen in such a way that they reflect the broad range of stakeholder groups) is sufficient to approach the proximal range of constructs of the stakeholder community represented by the sample.

Cumulative number of unique constructs elicited

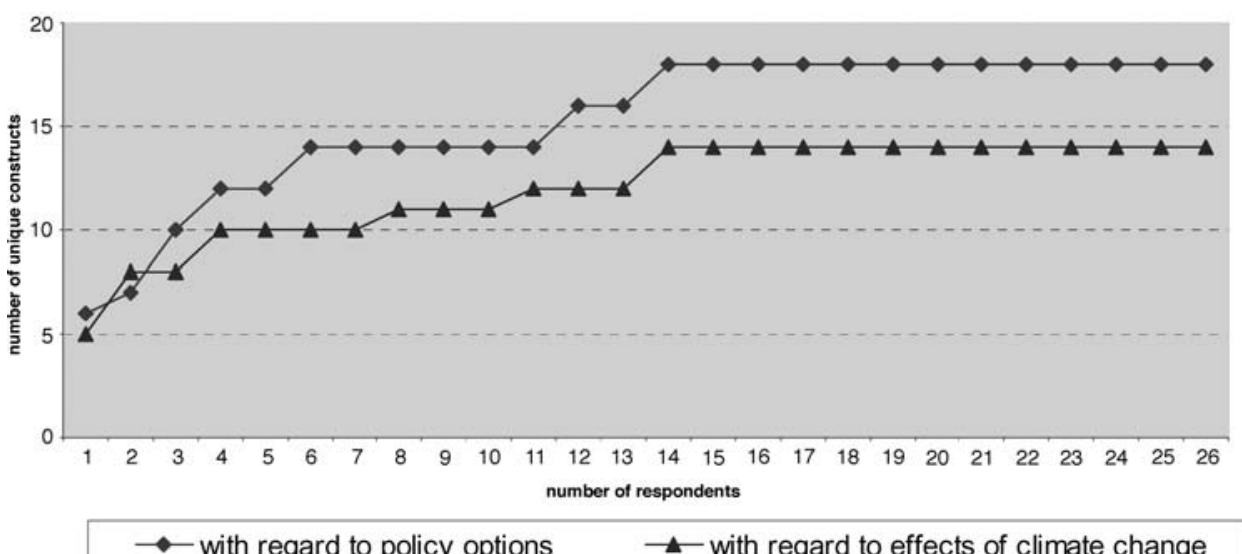

Figure 2. The cumulative number of unique constructs with regard to policy options (upper line) and effects of climate change (lower line) elicited from stakeholders interviewed in the Risk Approaches project clearly demonstrates the saturation rule. 
Table III summarises the various methods for inclusion of stakeholder knowledge and perspectives used in the IA processes discussed and maps on what key features they differ from each other.

\section{In What Way and to What Extent Did Boundary Work Occur in These Processes?}

The IA projects we looked at differ in the roles and competencies implicitly or explicitly attributed to each of the participants in the process (scientists, policymakers, stakeholders). A comprehensive analysis of the phenomenon of boundary work is beyond the scope of this paper and requires more empirical research. We will limit ourselves here to a few diagnostic illustrative observations of obvious differences in the design of the case projects, which reflect boundary work.

The COOL project shows the strongest boundary work leading to the sharpest demarcation of roles and competencies of participants: scientists and policy-makers had set a prior goal for the back casting exercises (namely $80 \% \mathrm{CO}_{2}$ emission reduction by the year 2050, compared to 1990 levels). Note that this was not a goal with any legal status, it was just a hypothetical imagined goal based on what some policy-makers and climate experts in the Netherlands believed to be necessary for the long term. The stakeholders' role was narrowed down to discussing strategic combinations of technological options (which constitutes yet another restriction of domains by excluding behavioural options and cultural change) to arrive at that goal. Within COOL, scientists played an active role (and they have been implicitly attributed exclusive competence) in bringing in expertise on present and future emission reduction technologies (potentials, expected costs, etc.) and performing consistency checks on the scenarios that have been developed in the dialogues. The stakeholders' role was limited to bringing in sector specific knowledge on the feasibility and implementability of technological changes.

A different approach to demarcating the domains where participants can bring in their views and wisdom can be identified in the ULYSSES project, which has been the most open project with no boundary setting in advance. Within the ULYSSES project, the scientist's role was made deliberately passive. A group moderator moderated the focus groups whereas the use of IA computer models in the focus groups was moderated by a model moderator. The group moderator was in charge of guiding the discussions, while avoiding an expert role. The model moderator presented the computer model and guided the specific discussions during the computer interaction period, also avoiding an expert role. The most important task of the model moderator was to present the computer model in a supportive way for the IA participatory debate. Participants' comments and their discussions indicated to the model moderator whether participants received - not necessarily accepted - the insights being conveyed. 


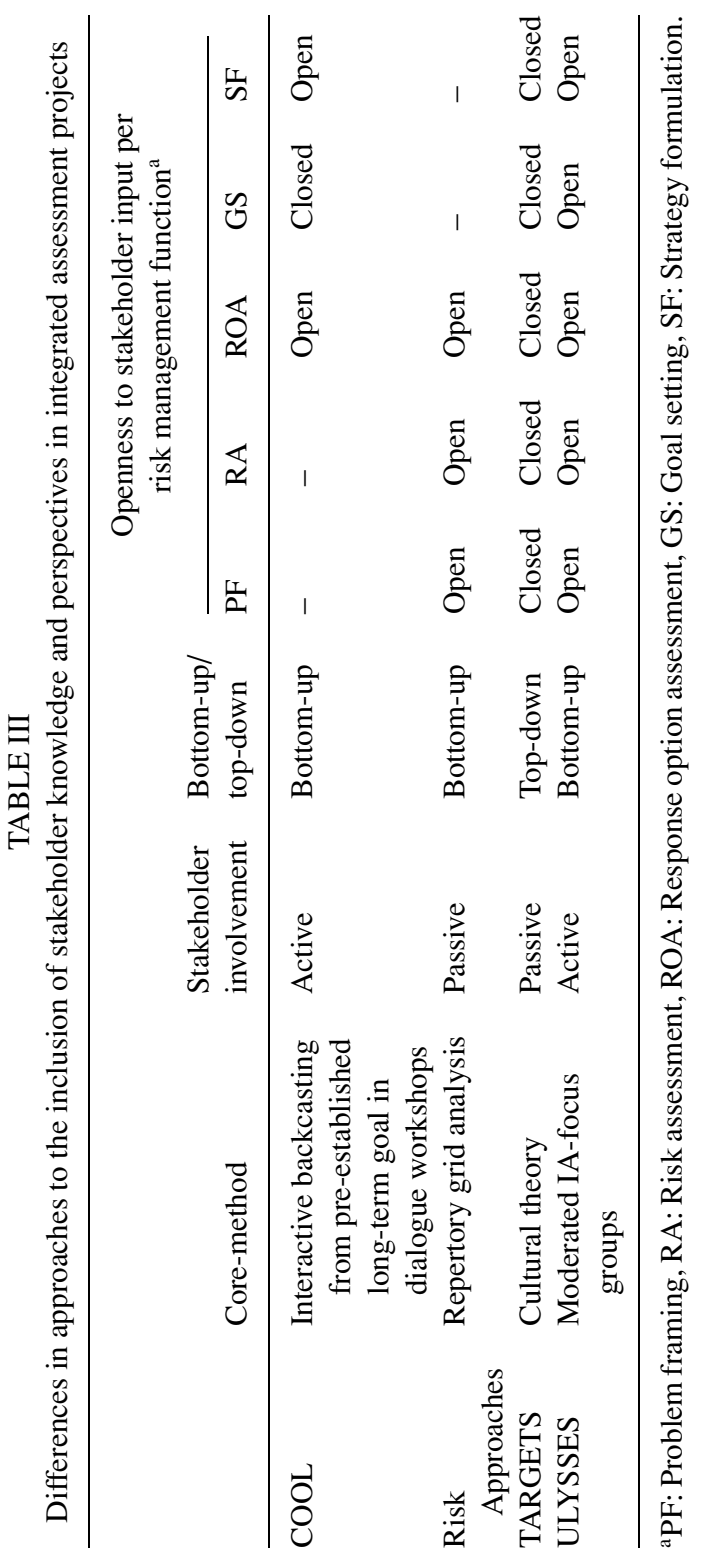


ULYSSES explicitly aimed at opening up the science: whatever the range of the computer model options (with regard to input and output variables, action and policy options), the model moderator was explicitly instructed not to limit discussions to what the model considers nor to the model reasoning. In this regard, the model moderator asked questions such as: 'Which other aspects not included in this model do you think are worth considering?' (Dahinden et al., 2003). In that sense ULYSSES has been a typical post-normal science exercise, acknowledging that in post-normal problems the process benefits from keeping the boundaries between domains of competence fuzzy.

In TARGETS, stakeholder perspectives can be seen reflected in issues that traditionally belonged to the scientific domain only. For example, different parameter values for climate sensitivity were assumed for each of the perspectives (Individualist, Egalitarian and Hierarchist). However, when assuming model relationships and model parameters consistent with the perspectives only model relations and quantities were chosen that can be found in the range of (the at that time) existing scientific publications (Van Asselt and Rotmans, 1997). This means that stakeholder perspectives that are not supported by any existing scientific finding (i.e., located outside the range) are not included. The developers of TARGETS note that although they see objectivity and subjectivity as relative concepts, they consider "scientific knowledge to be more 'objective' than other systems of belief about the natural and social world" (Van Asselt and Rotmans, 1997; p. 219).

With regard to the Risk Approaches project it can be said that the project as a whole was aimed at opening up the boundary between the science and the nonscience domain. In the project constructs that stakeholders use to think about climate change were identified and used to evaluate to what extent present day climate risk assessments address these dimensions. The results were translated into recommendations for scientists involved in the field of risk assessment of climate change (Van der Sluijs et al., 2002). It was thus elicited from non-scientific stakeholders what scientific and socio-political dimensions a risk assessment should address. By bringing forward risk dimensions that are scientific in nature (such as the irreversibility of effects), the stakeholders cross the border with science. Non-scientific stakeholders can most clearly be seen entering the scientific domain in the final workshop of the project, where they discussed the demand and supply side of risk-assessments together with scientists. Several scientific issues that according to the non-scientists should get more attention in climate risk assessments were brought forward (e.g., addressing non-linearity, surprise and the anthropogenic contribution to climate change) (Van der Sluijs et al., 2002). From our own observations during the workshop we can conclude that with regard to some issues the scientists initially took a defensive position. Their comments indicated that they regarded including certain aspects not to be scientifically sound. On the other hand, the non-scientific stakeholders indicated that they would like the scientists to cross the border of the scientific domain and enter the political debate by expressing how they feel about climate change, thereby not restricting themselves to what can be scientifically 
proven (e.g., by addressing the relationship between anthropogenic climate change and extreme weather events).

\section{How can Stakeholder Knowledge and Perspectives Best be Included?}

As was shown in the previous sections, stakeholders and their knowledge and perspectives can be involved in Integrated Assessments in very different ways. In spite of the experiences of previous processes and insight into the advantages and disadvantages of different process designs, it is impossible to give a generic blueprint on which methods and approaches to use in which situations, since each IA process has its own dynamics and purposes.

However, when designing an IA process, the suitability of the approaches we identified in Section 3 can be considered in view of the objectives one may have with the involvement of stakeholder knowledge and perspectives; the contribution of the IA to the overall risk management process; and the available resources. This will be discussed in Section 5.1. In this section we will also discuss the issue of boundary work in relation to the choice for an approach. Specific problems with the incorporation of stakeholder input regarding the approaches are addressed in Section 5.2.

\subsection{SELECTING AN APPROACH}

\subsubsection{Selecting an Approach in View of the Objectives}

In Section 2, we discussed motives for including stakeholder knowledge and perspectives when dealing with a post-normal problem: enhancing the quality; obtaining public support and legitimacy; and attaining democracy. These motives can also be viewed as objectives for involving stakeholder views.

The choice of objectives of an IA process imposes certain requirements on the design of the process. If, for instance, the main goal of involving stakeholders is to improve quality by including the local knowledge of the stakeholders, it is imperative to use a bottom-up approach: the specific knowledge of the stakeholders will not be found in the ideal-type descriptions that are used in top-down approaches. The COOL-project, which identified sector-specific information from the stakeholders, could therefore not have been designed with a top-down approach. Further, it seems questionable whether passive stakeholder involvement is suitable for a process in which democracy ${ }^{2}$ is a major objective, since in case of passive involvement it is the IA experts and their clients only that have the power to select the stakeholder input and draft the conclusions of the IA process.

\subsubsection{Selecting an Approach in View of the Contribution to the Overall Risk Management Process}

An IA can play a role in the overall (national, regional or global) risk management process in different ways. The IA can range from a broad exploration of the problem 
at hand to a process that is closely connected to the ongoing policy process. In the four cases we examined, TARGETS can be seen as an example of an IA of an exploratory nature, and COOL as an example of an IA that is somewhat related to the national policy process, since it focuses mainly on strategy formulation. None of the projects was closely connected to an ongoing policy process.

Top-down approaches and passive stakeholder involvement seem to be suitable for exploratory studies: they allow for a range of perspectives on a given problem to be systematically examined. Since it is the spectrum of perspectives that is important, passive involvement of the stakeholders' knowledge and perspectives can well be used. When an IA is closely related to a process of policy formulation, active involvement will often be preferable over passive involvement, since it actively enhances chances for public support for policies that are formulated. It may also enhance the willingness to take actions to deal with the problem at hand. Also the democratic nature of the policy process as a whole may be improved by actively involving stakeholders in an IA that is closely related to policy formulation. However, a passive and top-down approach can be useful and refreshing in closely policy related IA processes in which controversies have risen to such a level that they are frustrating fruitful stakeholder interaction.

\subsubsection{Selecting an Approach in View of the Available Resources}

In general, it can be stated that open, active involvement of stakeholders in the IA process will require more resources than a closed process and passive involvement. In case of active involvement meetings with the stakeholders have to be organised and a substantial investment has to be done in building trust relationships with and among the participating stakeholders. When involving stakeholders in the "scientific domain', effort will also have to be put in raising their (lay) knowledge level to a level at which the stakeholders are able to effectively make a contribution. Determining the end terms of a certain risk management function among the IA experts and the initiators of the IA process is likely to be less time and money consuming then leaving the end terms open for the stakeholders to co-decide.

Not only time and money can be seen as resources, also the capacity of getting stakeholders to become involved in the IA can be seen as a resource. In the Risk Approaches project, for instance, it turned out to be difficult to involve certain important Dutch stakeholders regarding climate change. Their willingness to become involved in yet another IA process was low, since they had already participated several times in participatory processes regarding climate change in the past, on which they had spent considerable time and effort.

\subsubsection{Boundary Work and the Selection of an Approach}

When choosing approaches for an IA process, IA experts should be aware of the possibility that their choices may partly be influenced by a form of boundary work. For instance, the choice to keep the risk assessment function closed may be partially determined by a tendency to keep stakeholders out of the scientific domain. The 
choice for passive stakeholder involvement in an IA process may be partly determined by the idea that stakeholders will not be capable of contributing directly to the scientific domain in the IA process, but that it would be better for the IA experts to collect their ideas and feed them into the IA process. A preference for a topdown approach can also be co-determined by a desire to keep stakeholders out of the scientific domain. Especially when choosing a closed, passive and/or top-down approach it seems valuable for the designers of the IA process to examine whether boundary work may have played a role in making the decision for this approach, and to examine whether the approach itself may cause boundary work of some form in the IA process.

\subsection{PROBLEMS WITH THE INCORPORATION OF STAKEHOLDER INPUT RELATED TO THE APPROACHES}

The incorporation of stakeholder knowledge and perspectives in IA processes can fail in three ways:

- stakeholders are not able or do not have the opportunity to make a (direct or indirect) contribution to the IA process; their knowledge and perspectives thus do not reach the IA experts;

- the stakeholders' knowledge and perspectives are not adequately interpreted or represented in the process by the IA experts; the knowledge and perspectives that the IA experts bring into the IA process thus do not match the knowledge and perspectives of the stakeholders;

- the stakeholders' knowledge and perspectives are not properly incorporated in the IA process; the stakeholders' knowledge and perspectives are thus not well reflected in the outcomes of the IA.

Not all approaches run the same level of risk regarding these three problems. Below, it is discussed per type of problem which approaches seem to be extra vulnerable to these problems.

\subsubsection{Not Able to Make a Contribution}

An obvious case of not having the opportunity to make a contribution is a risk management function that is closed. A closed problem-framing function may result in type III errors, where the wrong problem is being assessed in the IA process. In open risk management functions, a possible problem is that only certain stakeholders have the opportunity to contribute. With regard to integrated assessments regarding climate change, often the same persons are invited to participate in the process as stakeholders. Always involving the same well-known, 'high profile' stakeholders can be viewed as a pitfall as it is likely to generate groupthink (Janis, 1982) and anchoring (Van der Sluijs et al., 1998). New stakeholders or new representatives may bring in valuable new insights in the processes. 
In case of a passive approach, it is the IA experts that determine how and what information is elicited from the stakeholders. Consequently, stakeholder contributions that are not addressed by the experts' elicitation process are left out, and not able to enter the IA process. In case of an active approach the stakeholders have a more direct role in the contribution of their knowledge and perspectives. However, they may not be able to contribute or may have the feeling of not being able to contribute to the IA process if the stakeholders lack expertise. In case of a passive approach the stakeholders themselves do not have to actively bring their ideas to the front, but IA experts elicit their ideas, thereby possibly bridging part of the lack of expertise.

Boundary work may play a role in this category of problems, since the tendency to keep stakeholders out of a certain territory may lead to denying them the opportunity to make a contribution.

\subsubsection{Not Adequately Interpreted or Represented}

Compared to an active approach, a passive approach creates an extra risk of misinterpretation or mis-representation of stakeholder knowledge and perspectives. In case of active involvement, stakeholders are able to provide direct feedback during the IA with respect to the interpretation and representation of their input. Active involvement thus can also help reduce the risk of type III errors, since it allows the IA experts to interactively analyse how stakeholders view the problem at hand.

In a top-down approach, there is a risk that stakeholders do not recognise their perspectives in the ideal-types being used. They may feel that their perspectives thus are not adequately represented by the ideal-types. Besides this, there is also a risk that the categories are misapplied in a certain assessment, since the theoretical categories that are being used will often stem from a field that is relatively distant from the IA experts' fields (Risbey et al., 1996).

\subsubsection{Not Properly Incorporated}

The risk of not properly incorporating stakeholder knowledge and perspectives seems higher in case of a passive approach as compared to an active approach, due to the lack of opportunity for stakeholders to give feedback on the way in which their ideas are taken into account in the IA results.

Boundary work may cause problems of this nature, if the IA experts decide that certain stakeholder input has to be left out as they are to their opinion not qualified to deliver input on the scientific domain.

These three types of problems may jeopardise the objectives of involving stakeholder ideas. With any type of problem it can be said that the quality of the IA process, in terms of the involvement of stakeholder views, decreases. Whether the objectives of public support, legitimacy and democracy suffer from these problems depends on the perception of the stakeholders. If the stakeholders feel that they had the chance to contribute, and that their input has been represented and incorporated 
satisfactory, these objectives do not have to suffer, irrespective of whether the stakeholders' perception is right or not.

Awareness regarding these potential problems while selecting and implementing approaches will enable IA experts to pay extra attention to specific aspects in the design of the IA process to avoid or deal with these potential problems.

\section{Discussion and Conclusions}

IA processes in which stakeholder views are involved are mostly complex, consist of several phases and each IA process has its own dynamics. This makes comparison of the handling of stakeholder knowledge and perspectives difficult. The complexity and individual character of IA processes also makes it difficult to draft generic recommendations on what works best. In this paper we discussed four recent IA processes from which we identified different approaches for including stakeholder knowledge and perspectives in the IA process.

We addressed the following questions:

- What are motives for involving stakeholder knowledge and perspectives in IA of climate change?

- How have stakeholder knowledge and perspectives been included in IA of climate change?

- In what way and to what extent did boundary work occur in these IA processes?

- How can stakeholder knowledge and perspectives best be included in IA of climate change?

We argued that it is important to include stakeholder knowledge and perspectives both in view of the nature of the problem of climate change, and in view of the developments in the policy field regarding climate change. The climate problem is of a post-normal nature. Hence, taking the views of stakeholders into account in the IA process is necessary to enhance the quality of the assessment, to legitimise action taken in the policy process and the science that underpins the choice for that action, and to facilitate a democratic approach to the problem. With regard to policy processes regarding climate change we showed that the initially successful scientotechnical approach to IA met its limitations over time. More and more stakeholders became involved in the debate and in the current phase of the policy process, know-how has to be acquired, trust relations have to be built between parties involved, and there has to be active support from people that are affected by policies that are considered. Here, the previously mentioned motives of legitimisation and democracy can clearly be seen.

The four IA projects we explored in this study varied in the extent to which and the way in which the stakeholders' knowledge and perspectives were brought into the project, and the nature of the involvement of stakeholders. The first major difference we found between IA projects is whether the stakeholders are involved 
actively, i.e., taking active part in the assessment itself (as in COOL, ULYSSES) or passively: the IA experts make an inventory of stakeholder knowledge and perspectives and subsequently incorporate these in the assessment (as in Risk Approaches and TARGETS). The second difference we found between IA projects is the use of a top-down approach (starting from general classifications and translating this to specific issues; as in TARGETS) or a bottom-up approach (starting with nongeneralised ideas on specific issues; as in ULYSSES, Risk Approaches and COOL). The degree of openness of different functions of the IA process for stakeholder participation is the third difference we encountered. The latter varies from completely open, as in the ULYSSES and Risk Approaches projects, to strictly demarcated subdomains where participants can bring in their expertise (as in COOL, and through the use of ideal-types in TARGETS). This limiting of the input of participants to specific sub-domains can be seen as a form of boundary work, where domains are shielded off for either scientific or non-scientific stakeholders. In the ULYSSES and Risk Approaches project stakeholders were actively encouraged to cross the boundaries of the scientific and policy domain.

Although other techniques and methods for involving stakeholder views would have been encountered had other cases been selected, it is likely that a different selection of IA projects would have shown the same differences in approaches to involving stakeholder views.

When selecting approaches for including stakeholder knowledge and perspectives in a new IA process, several factors are important: the objectives for involving stakeholder views, the contribution of the IA to the overall risk management process, the available resources, and the issue of boundary work.

We identified the following objectives for involving stakeholder views: enhancing the quality; obtaining public support and legitimacy; and attaining democracy. Some combinations of objectives and approaches do not match. For instance, an IA process with the idea of contributing to a democratic manner of tackling a problem will not be served by a passive approach, since this approach implies that only the IA experts and their clients have the power to select the stakeholder input and draft the conclusions of the IA process. The approaches that are suitable for an IA process also depend on the position that the IA takes within the overall national, regional or global risk management process, which can range from a broad exploratory study to a process that is closely related to the policy process. For exploratory studies top-down approaches and passive involvement seem to be very suitable. When an IA process is closely related to a process of policy formulation, active involvement and bottom-up approaches seem to be more suitable, unless unsolvable controversies are involved. The resources that are available for the IA process may limit the possibilities for applying certain approaches. Open processes and active stakeholder involvement tend to require more time and money. Also, the capacity to get stakeholders involved can be seen as a resource. There is a possibility that the choices for approaches are partly influenced by a form of boundary work: IA experts may reach for closed, top-down and passive approaches when they think 
that the stakeholders are not competent to contribute to certain domains. IA experts should consider whether this may have played a role in the design of the IA process.

During each IA process with stakeholder input three problems can occur with respect to the incorporation of stakeholder knowledge and perspectives:

- stakeholders are not able to make a contribution to the IA process;

- the stakeholders' contribution is not adequately interpreted or represented in the process by the IA experts;

- the stakeholders' contribution is not properly incorporated in the IA process.

The extent to which the different risk management functions are opened up to input from stakeholders, the extent to which the stakeholders themselves are involved in bringing in their knowledge and perspectives, and their ability to give feedback during the IA process determine the extent to which these problems may occur in an IA process. Hence, the approaches we identified differ in their susceptibility to these problems. The occurrence of the problems mentioned may jeopardise the objectives of involving stakeholder input.

Awareness of these potential problems will allow IA experts to adjust their design and implementation of the methods they use to deal with this.

In the practice of participatory processes, the emphasis is often on involving stakeholders in the response option assessment function of the risk management process. However, including their views in the problem framing, risk assessment, goal setting and strategy formulation function can be beneficial. Involving stakeholder knowledge and perspectives in the problem-framing function reduces the risk of type III errors. In case of type III errors, the quality of the assessment will be affected since the wrong problem has been assessed. In addition, it will be difficult to obtain public support for the IA, and the IA runs the risk of not being perceived as legitimate. With regard to public support and legitimacy it is also important to involve stakeholders in the goal setting and formulation function. Involvement in the risk assessment function is important to the quality of the process, since stakeholders can contribute to the process with valuable knowledge and perspectives on the problem.

In this study we explored how the ideas of stakeholders can be involved throughout IA processes. Unlike previous studies concerning PIA projects our focus was not on specific methods for stakeholder involvement, but rather on the characteristics of different approaches for including stakeholder knowledge and perspectives. A second distinction with previous studies is that our emphasis is on the involvement of the knowledge and perspectives of stakeholders, not on the involvement of stakeholders. We argued that passive and top-down approaches are valuable ways for involving stakeholder ideas, especially in exploratory studies and in situations where the policy process seems stuck due to insolvable controversies. Our study thus goes beyond an analysis of PIA projects. With our brief analysis of issues related to boundary work, we hope to raise awareness that boundary work may play a role in the process design of IA processes with stakeholder input. The way in which 
an IA process is set up may also enhance tendencies to keep certain stakeholders out of domains of competence.

Several issues regarding the involvement of stakeholder knowledge and perspectives were not addressed in our study. How to deal with the varying quality of the input of stakeholders is an important issue, which to our opinion needs more research. An issue related to this is how to deal with the varying levels of knowledge of the stakeholders.

To our knowledge there have so far not been any IA projects with stakeholder involvement that were directly linked to the policy process of climate change. The projects carried out in the past have been of a more or less experimental nature and have mainly had the function of furthering and improving IA practice. Whether IA processes with stakeholder input can establish a well defined role in local, regional and global policy processes will depend on further developments in the policy field and on further developments in the practice of IA. With this paper we hope to have contributed some insights and guidance in process design that can improve the involvement of stakeholder knowledge and perspectives, in particular in view of the objectives for involvement, in view of the role of an IA process in the overall risk management process of climate change, and in view of considerations regarding boundary work.

\section{Acknowledgement}

We would like to thank Wim Turkenburg for his comments on an earlier draft, which greatly helped to improve the structure and clarity of our paper. We also thank Jerry Ravetz and Dale Rothman for their useful comments on the first submitted version.

\section{Notes}

\footnotetext{
${ }^{1}$ In practice, IA addresses only part of 'the whole set' of cause effect interactions because analysts always make a selection and simplify and because the knowledge on and understanding of causal relations in complex environmental problems is only partial and major knowledge gaps prevail.

${ }^{2}$ Democracy here is used in the sense of allowing the people concerned to contribute to the process, as opposed to achieving democracy through a system of representative agents.
}

\section{References}

Bailey, P., Gough, C., Chadwick, M., and McGranahan, G.: 1996, Methods for Integrated Environmental Assessment: Research directions for the European Union, Stockholm Environment Institute, Stockholm.

Berk, M., Den Elzen, M., and Metz, B.: 2001, Differentiatie van Toekomstige Inspanningen in het kader van het Klimaatverdrag: Enkele Verkennende Berekeningen ten Behoeve van het NMP-4, RIVM, Bilthoven, The Netherlands, RIVM report No. 728001018. 
Bolin, B., Döös, B. R., Jäger, J., and Warrick, R. A.: 1986, The Greenhouse Effect, Climatic Change and Ecosystems, SCOPE 29, Wiley, Chichester.

Dahinden, U., Querol, C., Jäger, J., and Nilsson, M.: 2003, 'Citizens interaction with computer models', in Kasemir, B., Jäger, J., Jaeger, C. C., and Gardner, M. T. (eds.), Public Participation in Sustainability Science: A Handbook, Cambridge University Press, Cambridge.

Darier, É., Jaeger, C., Kasemir, B., Schüle, R., Shackley, S., and Wynne, B.: 1998, Contributions to Participatory Integrated Assessment, Darmstadt University of Technology, Darmstadt, Germany, ULYSSES Working Paper WP-98-1.

Douglas, M. and Wildavsky, A.: 1982, Risk and Culture, University of California Press, Berkeley.

Dunn, W. N.: 1997, Cognitive Impairment and Social Problem Solving: Some Tests for Type III Errors in Policy Analysis, Graduate School of Public and International Affairs, University of Pittsburgh, Pittsburgh.

Dunn, W. N.: 1998, Pragmatic Eliminative Induction: Proximal Range and Context Validation in Applied Social Experimentation, Graduate School of Public and International Affairs, University of Pittsburgh, Pittsburgh, GSPIA working paper 001.

Dunn, W. N.: 2001, 'Using the Method of Context Validation to Mitigate Type III errors in Environmental Policy Analysis', in Hisschemöller, M., Hoppe, R., Dunn, W. N., and Ravetz, J. R. (eds.), Knowledge, Power, and Participation in Environmental Policy Analysis, Policy Studies Review Annual, Volume 12, Transaction Publishers, New Brunswick, NJ, pp. 417-436.

Fransella, F. and Bannister, D.: 1977, A Manual for Repertory Grid Technique, Academic, London.

Funtowicz, S. O. and Ravetz, J. R.: 1992, 'Three types of risk assessment and the emergence of post-normal science', in Krimsky, S. and Golding, D. (eds.), Social Theories of Risk, Greenwood, Westport, CT, pp. 251-273.

Funtowicz, S. O. and Ravetz, J. R.: 1993, 'Science for the post-normal age', Futures 25, 739-755.

Funtowicz, S. O. and Ravetz, J.: 1996, 'Risk Management, post-normal science, and extended peer communities', in Hood, C. and Jones, D. K.C. (eds.), Accident and Design, Contemporary Debates in Risk Management, UCL Press, London, Bristol, PA, pp. 172-182.

Gieryn, T. F.: 1983, 'Boundary-work and the demarcation of science from non-science: Strains and interests in professional ideologies of scientists', American Sociological Review 48, 781795.

Hisschemöller, M., De Boer, J., Breukels, M., Dunn, W. N., and Van der Sluijs, J. P.: 2000, Climate Risk Assessment: Evaluation of Approaches, Working document 1, Department of Science Technology and Society, Utrecht University, Utrecht, The Netherlands.

Hisschemöller, M., Van de Kerkhof, M., Annema, J. A., Folkert, R., Kok, M., Spakman, J., Faaij, A., Treffers, D. J., De Jager, D., Jeeninga, H., Kroon, P., Seebregts, A., and Spanjersberg, M.: 2002, Climate OptiOns for the Long-term (COOL) - National Dialogue, IVM-VU, Amsterdam, The Netherlands, IVM report No. E-01-05 and NRP report No. 410200116.

Janis, I. L.: 1982, Groupthink: Psychological Studies of Policy Decisions and Fiascoes, Houghton, Mifflin, Boston.

Jasanoff, S.: 1990, The Fifth Branch: Science Advisers as Policy Makers, Harvard University Press, Cambridge, MA.

Kates, R. W., Hohenemser, C., and Kasperson, J. X. (eds.): 1985, Perilous Progress: Managing the Hazards of Technology, Westview Press, Boulder.

Kasemir, B., Dahinden, U., Gerger, Å., Schüle, R., Tàbara, D., and Jaeger, C.: 1999, Fear, Hope and Ambiguity: Citizens' Perspectives on Climate Change and Energy Use, Darmstadt University of Technology, Darmstadt, Germany, ULYSSES Working Paper WP-99-1.

Kasemir, B., Jäger, J., and Jaeger, C. C.: 2003, 'Citizen participation in sustainability assessments', in Kasemir, B., Jäger, J., Jaeger, C. C., and Gardner, M. T. (eds.), Public Participation in Sustainability Science: A Handbook, Cambridge University Press, Cambridge, pp. 3-36.

Mostert, E.: 2003, 'The challenge of public participation', Water Policy 5, 179-197. 
Nakicenovic, N. and Swart, R. (eds.): 2000, Special Report on Emissions Scenarios: A Special Report of Working Group III of the Intergovernmental Panel on Climate Change, Cambridge University Press, Cambridge.

Querol, C., Gerger, A., Kasemir, B., and Tàbara, D.: 1999, Citizens' Recommendations for Addressing Climate Change: A Participatory Integrated Assessment Exercise in Europe, Darmstadt University of Technology, Darmstadt, Germany, ULYSSES Working Paper WP-99-4.

Raifa, H.: 1968, Decision Analysis, Addison-Wesley, Reading, MA.

Ravetz, J. R. and Funtowicz, S. O.: 1999, 'Post-normal science - An insight now maturing', Futures 31, 641-646.

Risbey, J., Kandlikar, M., and Patwardhan, A.: 1996, 'Assessing integrated assessments', Clim. Change 34, 369-395.

Rotmans, J.: 1998, 'Methods for IA: The challenges and opportunities ahead', Environ. Model. Assess. 3, 155-179.

Rotmans, J. and Dowlatabadi, H.: 1997, 'Integrated assessment modelling', in Rayner, S. and Malone, E. L. (eds.), Human Choice and Climate Change, Vol. 3. The Tools for Policy Analysis, Battle Press, Columbus, OH, pp. 291-377.

Rotmans, J. and De Vries, B.: 1997, Perspectives on Global Change, The TARGETS Approach, Cambridge University Press, Cambridge.

Sors, A., Liberatore, A., Funtowicz, S. O., Hourcade, J. C., and Fellous, J. L. (eds.): 1997, Proceedings of the International Symposium - Prospects for Integrated Assessment: Lessons Learnt from the Case of Climate Change, European Commission DG XII, Toulouse, France, October 24-26, 1996.

Sprinz, D. and Luterbacher, U.: 1996, International Relations and Global Climate Change, Potsdam Institute for Climate Impact Research, Potsdam, Germany, PIK report No. 21.

Stern, P. C. and Fineberg, H. V. (eds.): 1996, Understanding Risk, Informing Decisions in a Democratic Society, National Research Council, National Academy Press, Washington, DC.

The Social Learning Group: 2001, Learning to Manage Global Environmental Risks: A Comparative History of Social Responses to Climate Change, Ozone Depletion and Acid Rain, MIT Press, Cambridge, MA.

Toth, F. L. and Hizsnyik, E.: 1998, 'Integrated environmental assessment methods: Evolution and applications', Environ. Model. Assess. 3, 193-207.

Van Asselt, M. B. A. and Rotmans, J.: 1997, 'Uncertainties in perspective', in Rotmans, J. and De Vries, B. (eds.), Perspectives on Global Change: The TARGETS Approach, Cambridge University Press, Cambridge.

Van Asselt, M. B. A. and Rijkens-Klomp, N.: 2002, 'A look in the mirror: Reflection on participation in integrated assessment from a methodological perspective', Global Environ. Change 12, 167-184.

Van de Kerkhof, M.: 2004, Debating Climate Change. A Study on Stakeholder Participation in an Integrated Assessment of Long-Term Climate Policy in the Netherlands, Lemma Publishing, Utrecht, the Netherlands.

Van de Kerkhof, M., Hisschemöller, M., and Spanjersberg, M.: 2003, 'Shaping diversity in participatory foresight studies: Experiences with interactive backcasting in a stakeholder assessment on long-term climate policy in The Netherlands', Greener Manage. Int. 37, 85-99.

Van der Sluijs, J. P.: 1997, Anchoring Amid Uncertainty: On the Management of Uncertainties in Risk Assessment of Anthropogenic Climate Change, Ph.D. Thesis, Utrecht University, Utrecht, The Netherlands.

Van der Sluijs, J. P.: 2001, 'Integrated assessment models and the participatory challenge: The case of climate change', in Dunn, W. N., Hisschemöller, M., Hoppe, R., and Ravetz, J. R. (eds.), Knowledge, Power, and Participation in Environmental Policy Analysis, Policy Studies Review Annual, Vol. 12, Transaction Publishers, New Brunswick, NJ, pp. 317-348.

Van der Sluijs, J. P.: 2002, 'A way out of the credibility crisis of models used in integrated environmental assessment', Futures 34, 133-146. 
Van der Sluijs, J. P., Van Eijndhoven, J. C. M., Wynne, B., and Shackley, S.: 1998, 'Anchoring devices in science for policy: The case of consensus around climate sensitivity', Soc. Stud. Sci. 28, 291-323.

Van der Sluijs, J. P. and Lourens, P.: 2000, Climate Risk Assessment: Evaluation of Approaches, Working document 2, Department of Science Technology and Society, Utrecht University, Utrecht, The Netherlands.

Van der Sluijs, J. P., Hisschemöller, M., De Boer, J., and Kloprogge, P.: 2002, Climate Risk Assessment: Evaluation of Approaches, Synthesis Report, Department of Science Technology and Society, Utrecht University, Utrecht, The Netherlands, NW\&S report No. E-2002-96.

World Bank: 1996, The World Bank Participation Sourcebook, The World Bank, Washington.

World Meteorological Organisation: 1989, Proceedings of the World Conference on the Changing Atmosphere: Implications for Global Security, WMO, Toronto, 27-30 June 1988, report No. 710.

Yosie, F. T. and Herbst, T. D.: 1998, Using stakeholder processes in environmental decision-making: An evaluation of lessons learned, key issues and future challenges, Ruder Finn Washington, ICF Incorporated, Washington, http://www.gdrc.org/decision/nr98ab01.pdf

(Received 28 August 2003; in revised form 14 June 2005) 